\title{
Study of Some Physical Properties of Cellulose Fibers Using X-Ray Diffraction Techniques
}

\author{
Gajendra Nath Sarma ${ }^{1}$, Sanjib Karmakar ${ }^{2}$ \\ ${ }^{1}$ Department of Physics, Hojai College, Hojai, Assam, India \\ ${ }^{2}$ Department of Instrumentation \& USIC, Gauhati University, Assam, India
}

\begin{abstract}
The X-ray diffractogram of raw and degummed ginger (Zingiber officinale), turmeric (Curcuma longa) and eri (Samia cynthia ricini) fibers are taken at room temperature in an a X-ray Powder Diffractometer (Phillips, X'Pert Pro). It is found that the degree of crystallinity of the fibers increases due to degumming. The degree of crystallinity of ginger fibers is found to increase from $66.67 \%$ to $78.23 \%$, of turmeric fibers is found to increase from $69 \%$ to $78.8 \%$ and of Eri fibers is found to increase from $82.39 \%$ to $86.95 \%$ as a result of degumming.
\end{abstract}

Keywords: Zingiber officinale, Curcuma longa, Samia cynthia ricini, Degree of crystallinity

\section{Introduction}

Eri silk is one of the most important types of fibrous proteins having potential applications in textile and electrical industries ${ }^{1-5}$. The cellulose fibers such as ginger, Turmeric and Eri silk fibers are semicrystalline and hygroscopic in nature. The physical properties of these fibers have great importance in textile technology. The action of absorbed water and the influence of gum on crystalline structure of some cellulose fibers have been studied $^{6-8}$. The crystallographic behaviour of some cellulose fibers (pineapple, jute, cotton etc) have been observed at room tempersture as well as at different temperatures at which they are quenched and annealed ${ }^{9-}$ ${ }^{10}$.In the present investigation the raw and degummed Ginger, Turmeric and Eri fibers are subjected to X-ray diffraction to study their behaviour at room temperature.

\section{Sample Preparation}

Ginger (zingiber officinale) plants, Turmeric (curcuma longa) plants and Eri (samia cynthia ricini) cocoons have been collected from various parts of the north-eastern region of India. The fibers have been extracted from the middle portion of the stem of these plants and from the eri cocoons. One part of the raw ginger, turmeric and eri fibers (each fiber treated separately) were immerged in a mixture of Benzene and Alcohol (ratio 1:1) for six hours and then washed with distilled water and dried normally at room temperature. For ginger and turmeric, this part is then divided into two parts, one of which is boiled in $\mathrm{NaOH}$ solution at $2 \%$ concentration and the other at $6 \%$ concentration for 30 minutes. These fibers were then again washed with distilled water and dried normally. For eri, this part is also divided into two parts, one of them is boiled for 30 minutes with $2 \% \mathrm{NaOH}$ and the other part is boiled for the same time with $0.3 \% \mathrm{Na}_{2} \mathrm{CO}_{3}$. These eri fibers are also washed with distilled water and dried normally.

\section{Experimental Arrangement}

X-ray powder method is a suitable method to study the cellulose crystallinity. The diffraction peaks caused by cellulose crystals and from amorphous cellulose, hemicellulose, lignin, pectin and minerals are found at different positions in the diffractogram. For XRD, the crystalline diameter can also be estimated with X-ray diffraction based on the width of peaks representing the directions perpendicular to the fiber axis. The crystalline length can also be estimated on the width of peaks representing directions parallel to the fiber axis.

\section{Measurement}

The finely cut fiber samples were subjected to X-radiation $(\mathrm{Cu} \mathrm{K} \alpha$, wavelength $=1.54 \AA$ Á). The applied voltage and current to the X-ray tube were $40 \mathrm{KV}$ and $30 \mathrm{~mA}$ respectively. Programmable divergence slit with irradiated length of $8 \mathrm{~mm}$ were used during measurement with programmable receiving slit being used at the other end with slit height of $0.1 \mathrm{~mm}$; the incident beam mask was fixed at $10 \mathrm{~mm}$. but he diffracted beam mask was not used. Diffracted beam soller slit was fixed at 0.04 rad. Pulse height distribution for the detector at upper and lower levels were fixed at $80 \%$ and $35 \%$ respectively. The scanning range was taken from $10^{\circ}$ to $30^{\circ}$.

\section{Result and Discussion}

The X-ray diffractogram spectra of Ginger (raw and degummed), Turmeric (raw and degummed) and Eri (raw and degummed) are shown in fig.1, fig. 2 and fig. 3 respectively. The identical XRD spectra of the samples indicate that all these fibers possess similar characteristics. The interplanner spacings $\left(\mathrm{d}_{\mathrm{hkl}}\right)$, angle of diffraction $(2 \theta)$, peak intensity (I) and the degree of crystallinity of raw and degummed ginger fibers are shown in table 1. It is seen that the degree of crystallinity of ginger fibers increases due to degumming. The degree of crystallinity is more for degumming in $6 \% \mathrm{NaOH}$ than in $2 \%$ $\mathrm{NaOH}$ concentrantion. This might be due to the presence of water molecules in the amorphous region of hygroscopic fibers, which restrict the alignment of chain molecules and thus gives rise to strain in the crystalline region.

The interplanner spacings $\left(\mathrm{d}_{\mathrm{hkl}}\right)$, angle of diffraction $(2 \theta)$, peak intensity (I) and the degree of crystallinity of raw and degummed turmeric fibers are shown in table 2. The

Volume 6 Issue 1, January 2017 


\section{International Journal of Science and Research (IJSR) \\ ISSN (Online): 2319-7064}

Index Copernicus Value (2015): 78.96 | Impact Factor (2015): 6.391

degree of crystallinity of turmeric fibers are found to increase due to degumming. It is found that the degree of crystallinity is more in $6 \% \mathrm{NaOH}$ than in $2 \% \mathrm{NaOH}$. This may be due to the fact that, after degumming, the molecular chains of the turmeric fibers, which were restricted by gum, become free to rearrange and have more crystalline form.

The interplanner spacings $\left(\mathrm{d}_{\mathrm{hkl}}\right)$, angle of diffraction $(2 \theta)$, peak intensity (I) and the degree of crystallinity of raw and degummed eri fibers are shown in table 3. The degree of crystallinity of turmeric fibers are found to increase due to degumming. It is found that the degree of crystallinity is more in $0.3 \% \mathrm{Na}_{2} \mathrm{CO}_{3}$ than in $2 \% \mathrm{NaOH}$. This may be due to the reason that the molecular chains of the fibers, which were restricted by gum, becomes free to rearrange after degumming, and thus gives rise to strain in the crystalline region.

The method used to calculate the degree of crystallinity for all these fibers is same as used by Bora et $\mathrm{al}^{11-12}$.

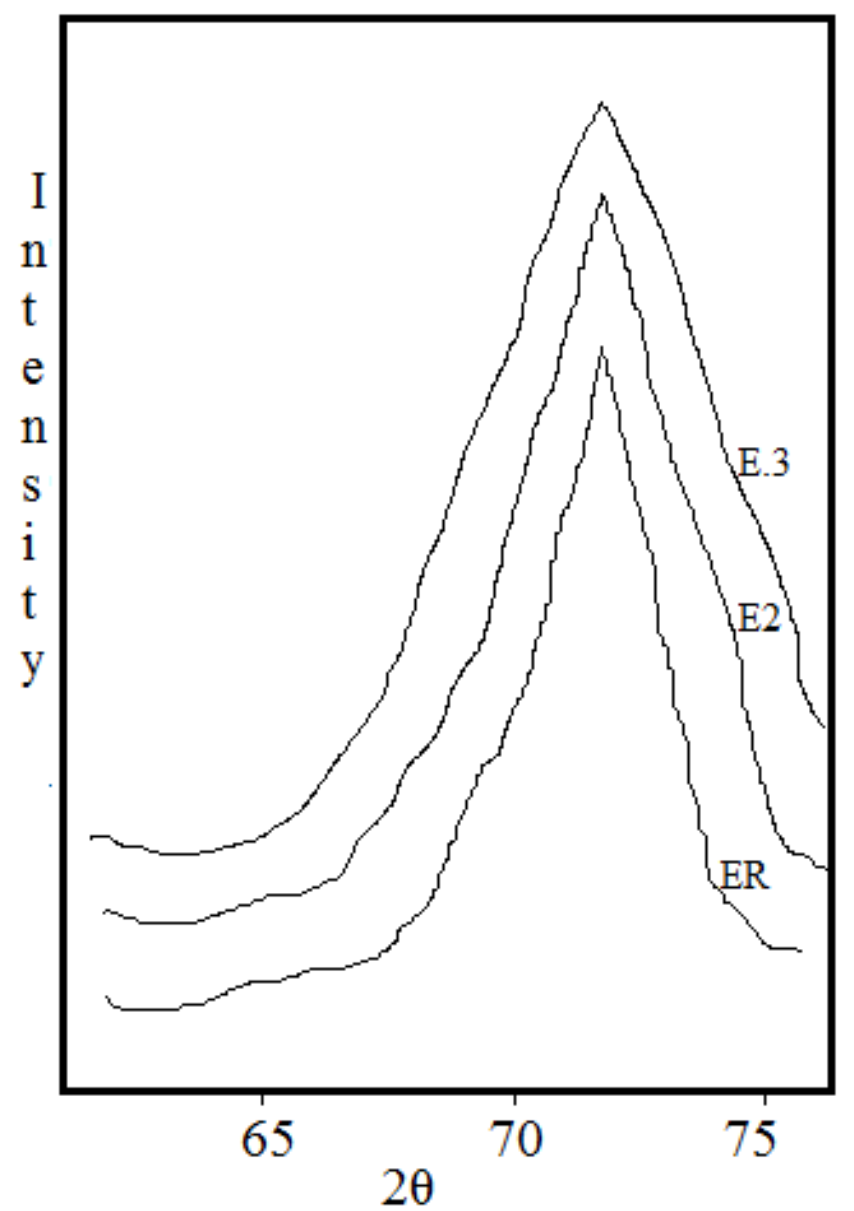

Figure 1

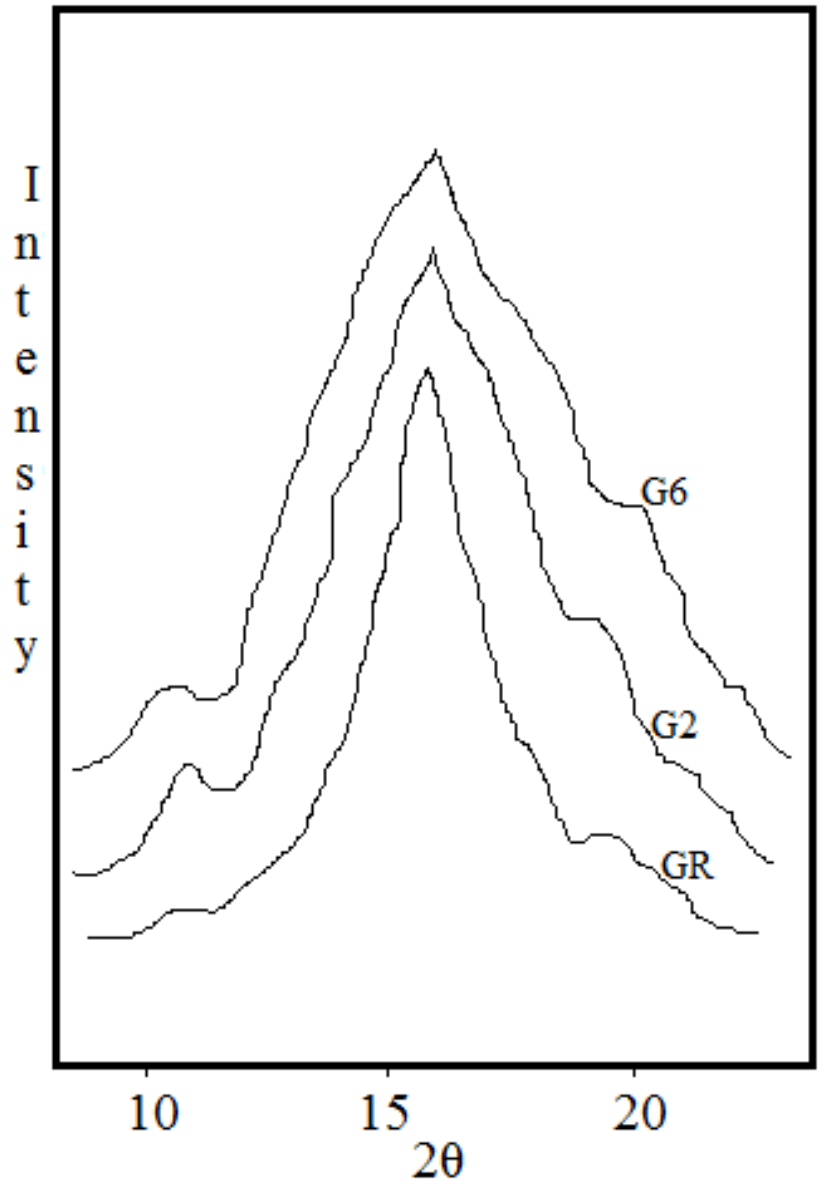

Figure 2

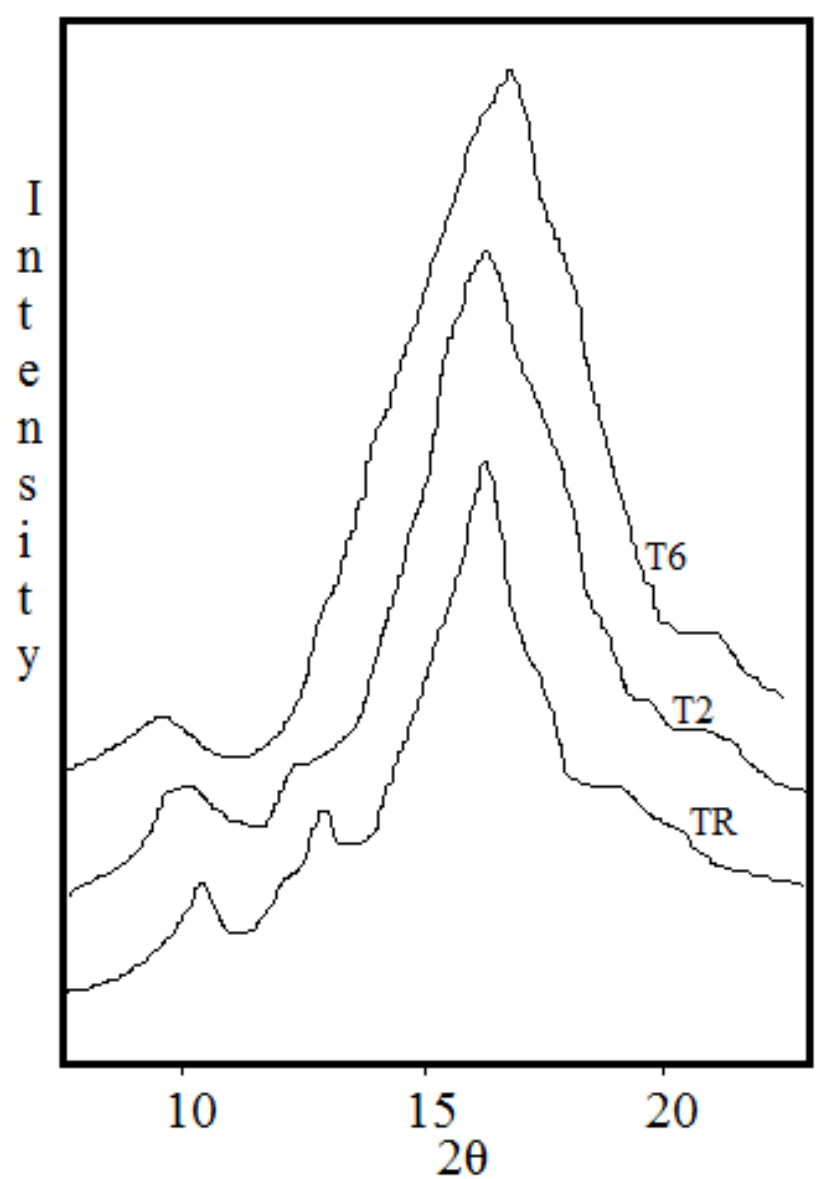

Figure 3

Volume 6 Issue 1, January 2017

www.ijsr.net

Licensed Under Creative Commons Attribution CC BY 


\section{International Journal of Science and Research (IJSR) \\ ISSN (Online): 2319-7064 \\ Index Copernicus Value (2015): 78.96 | Impact Factor (2015): 6.391}

(ER - eri raw, E2 - eri degummed by $2 \% \mathrm{NaOH}, \mathrm{E} .3$ - eri degummed by $0.3 \% \mathrm{Na}_{2} \mathrm{CO}_{3}$

$\mathrm{GR}$ - ginger raw, $\mathrm{G} 2$ - ginger degummed by $2 \% \mathrm{NaOH}$, G6 - ginger degummed by $6 \% \mathrm{NaOH}, \mathrm{TR}$ - turmeric raw,
T2 - turmeric degummed by $2 \% \mathrm{NaOH}, \mathrm{T} 6$ - turmeric degummed by $6 \% \mathrm{NaOH}$ )

Table 1: Parameters obtained from XRD spectrum for ginger raw and degummed fibers

\begin{tabular}{|c|c|c|c|c|c|}
\hline Sample name & Spacing $\mathrm{d}_{\text {hkl }}$ & Angle & $\mathrm{I}_{\max }$ & $\mathrm{I}_{\min }$ & DC\% \\
\hline Ginger raw & 4.17 & 21.7 & 138 & 46 & 66.67 \\
\hline Ginger degummed by 2\% NaOH & 4.17 & 21.7 & 364 & 96 & 73.63 \\
\hline Ginger degummed by 6\% NaOH & 4.11 & 22.1 & 372 & 81 & 78.23 \\
\hline
\end{tabular}

Table 2: Parameters obtained from XRD spectrum for turmeric raw and degummed fibers

\begin{tabular}{|c|c|c|c|c|c|}
\hline Sample name & Spacing $\mathrm{d}_{\text {hkl }}$ & Angle & $\mathrm{I}_{\max }$ & $\mathrm{I}_{\min }$ & DC\% \\
\hline $\begin{array}{c}\text { Turmeric } \\
\text { raw }\end{array}$ & 4.24 & 21.3 & 242 & 75 & 69.0 \\
\hline $\begin{array}{c}\text { Turmeric degummed by 2\% } \\
\mathrm{NaOH}\end{array}$ & 4.20 & 21.5 & 334 & 87 & 73.9 \\
\hline $\begin{array}{c}\text { Turmeric degummed by 6\% } \\
\mathrm{NaOH}\end{array}$ & 4.11 & 22.0 & 378 & 80 & 78.8 \\
\hline
\end{tabular}

Table 3: Parameters obtained from XRD spectrum for eri raw and degummed fibers

\begin{tabular}{|c|c|c|c|c|c|}
\hline Sample name & Spacing $\mathrm{d}_{\mathrm{hkl}}$ & Angle & $\mathrm{I}_{\max }$ & $\mathrm{I}_{\min }$ & DC\% \\
\hline Eri raw & 1.62 & 72.3 & 761 & 134 & 82.39 \\
\hline Eri degummed by $2 \% \mathrm{NaOH}^{2}$ & 1.62 & 72.3 & 911 & 133 & 85.46 \\
\hline Eri degummed by $0.3 \% \mathrm{Na}_{2} \mathrm{CO}_{3}$ & 1.62 & 72.5 & 921 & 120 & 86.95 \\
\hline
\end{tabular}

The variation of degree of crystallinity of ginger and turmeric fibers due to degumming is shown graphically in fig. 4 . The similarity of the graphs indicates that the rate of increase of $\mathrm{DC} \%$ is same for both the fibers.

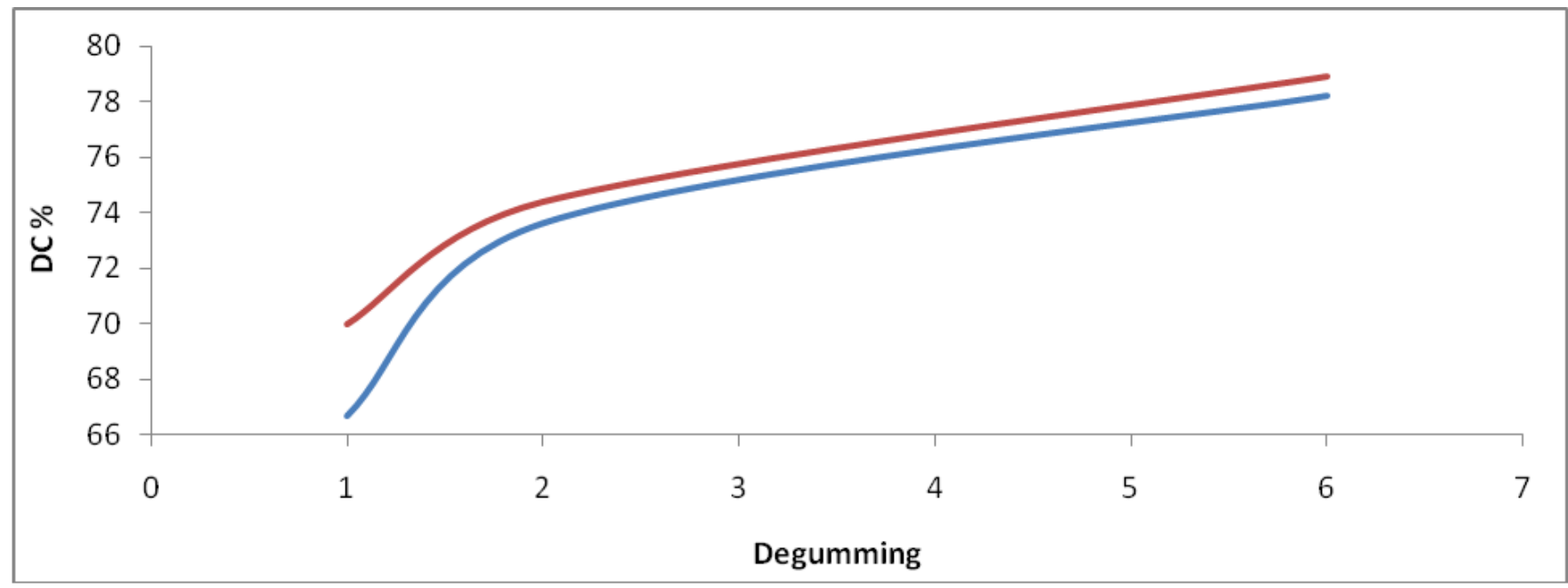

Figure 4: (Lower graph for ginger, upper graph for turmeric fiber)

\section{Conclusion}

It observes that the percentages of degree of crystallinity of raw and degummed fibers are different. For all the fibers the percentage of degree of crystallinity increases due to degumming. The degree of crystallinity of raw and degummed turmeric fibers is higher than that of the ginger fibers, but less than that of eri fibers. The increase of degree of crystallinity of fibers as a result of degumming is due to removal of water molecules from the amorphous region of the hygroscopic fibers.

\section{References}

[1] Bora M N, Bardoloi S, Talukdar D, Talukdar M and Talukdar C, Proc. of ATPC, held in Japan, August 2124, 2007

[2] Duswalt A A, 1974 Thermocimica, ACTA, 8, 15.

[3] Antal M J et al., 1980, combustion Sci. Technology, $21,141$.

[4] Bora M N, Baruah G C and Talukdar C, 1993, Thermocimica ACTA, 218, 435-443.

[5] Bora M N, Saikia D, Saikia R, Talukdar C, 1997, High temp- High pressure, vol 29, p 683-688.

Volume 6 Issue 1, January 2017

www.ijsr.net

Licensed Under Creative Commons Attribution CC BY 


\section{International Journal of Science and Research (IJSR)}

ISSN (Online): 2319-7064

Index Copernicus Value (2015): 78.96 | Impact Factor (2015): 6.391

[6] Gregorski K S, 1982 Proc $7^{\text {th }}$ Int. Conference on Anal,1, 90.

[7] Ray P K, 1967 Text Res. Journal, 37, 434.

[8] Ray P K, 1969 Journal, Applied Polymer Sci. Vol. 13, p 2593.

[9] Ray P K et al, 1975, J. Applied Polym Sc. 19, 1997.

[10] Bora M N, Talukdar C, 1992 Proc, the Fourth Asian Thermophysical Properties Conference, Beijing, Oct. 12-15.

[11] Bora M N, Talukdar C, Talukdar M, 1999, Indian J. of Fiber and Textile Research, vol 24, p 172-176.

[12] Bora M N, Bardoloi S, Saikia D, 1995, Proc. The Fouth ATPC, Tokyo, p739-742

Volume 6 Issue 1, January 2017

www.ijsr.net 